\title{
Dermal Carbon Monoxide Excretion in Neonatal Rats During Light Exposure
}

\author{
HENDRIK J. VREMAN, YURI KNAUER, RONALD J. WONG, MIU-LAN CHAN, AND DAVID K. STEVENSON \\ Department of Pediatrics, Stanford University School of Medicine, Stanford, California 94305
}

\begin{abstract}
Total body, head, and trunk carbon monoxide (CO) excretion rates were measured separately by gas chromatography in 1- to 7-d-old Wistar rat pups exposed to the dark and to mixed blue (one Special Blue-F20T12/BB) and white (two Cool WhiteF20T12/CW) fluorescent light or blue light emitting diode (LED) sources. During 48-min cycled exposures to the dark and to either light source, total body $\mathrm{CO}$ excretion rapidly increased 1.9- and 1.4-fold, respectively, over dark control levels. When CO excretion rates from the head and trunk were measured separately during exposure to either light source, $\mathrm{CO}$ excretion from the head did not change significantly; however, a large mean 4.4-fold increase in CO excretion from the trunk was observed. When light intensity delivered by the blue LED source was varied, we found that trunk CO excretion increased with increasing light intensities. In the presence of riboflavin $(10 \mu \mathrm{mol} / \mathrm{kg}$ ), total body $\mathrm{CO}$ excretion increased 2.8 and 2.1-fold during exposure to the mixed fluorescent light and blue LED sources, respectively. We conclude that light-induced elevations in total body $\mathrm{CO}$ excretion may be caused by transdermally excreted $\mathrm{CO}$, which is most likely produced through endogenous photosensitizer-mediated photooxidation of dermal biomolecules.

(Pediatr Res 66: 66-69, 2009)
\end{abstract}

$\mathrm{P}$ hototherapy has been considered safe and efficacious for treatment of neonatal jaundice and protection against bilirubin-related neurodevelopmental impairment (1). In a recent randomized controlled trial investigating the use of aggressive $v s$. conservative phototherapy for infants with extremely lowbirth weight (ELBW, $\leq 1500 \mathrm{~g}$ ) (2), efficacy was affirmed, but a question was raised regarding the safety of phototherapy for the smallest babies (501-750 g), who tended to have a higher mortality rate when treated with aggressive phototherapy. This observed increase in the rate of death for the smallest infants was also supported by a Bayesian analysis, and echoed findings published in 1985 (3), suggesting a relative risk of death of 1.49 (95\% CI, 0.93-2.40) for infants with birth weights below $1000 \mathrm{~g}$ treated with phototherapy using daylight fluorescent lights. However, neither of these studies showed statistical significance for this potentially worrisome finding of a serious side effect of light, which may have an apparent predilection for the most immature and translucent subjects.

Received December 11, 2008; accepted February 26, 2009.

H.J.V. and Y.K. contributed equally to this article.

Correspondence: Ronald J. Wong, M.D., Department of Pediatrics, Stanford University School of Medicine, 300 Pasteur Drive, Rm S230, Stanford, CA 94305; e-mail: rjwong@stanford.edu

Supported by the Mary L. Johnson Research Fund, Christopher Hess Research Fund, the L. H. M. Lui Research Fund, and National Institutes of Health (grants HL58013 and HL68703).
Nonetheless, there is biologic rationale for these findings, as the smallest infants are likely to be the most deficient in antioxidant defense and the most easily penetrated by light, which could promote harmful photochemical reactions (4-6). Ironically, light also reduces bilirubin levels, thereby further diminishing this source of endogenous defense against oxidation from other causes such as lipid peroxidation (7).

We have shown previously that carbon monoxide $(\mathrm{CO})$ is a significant product of photooxidation (8) and lipid peroxidation (9), and its production can be used as an index of these processes. In this study, we measured in vivo $\mathrm{CO}$ excretion rates, as an index of oxidation, in physically isolated body sections of Wistar rat pups exposed to a blue/white fluorescent or a blue light emitting diode (LED) light source and at different irradiances. $\mathrm{CO}$ excretion from the head was assumed to represent the sum of pulmonary and dermal $\mathrm{CO}$ excretion; whereas, $\mathrm{CO}$ excretion from the trunk was assumed to represent primarily dermal $\mathrm{CO}$ excretion. Comparison of $\mathrm{CO}$ excretion in the dark vs. light served as an index of possible photooxidation processes most likely occurring in the upper layers of the skin.

\section{MATERIALS AND METHODS}

Animals. Thirty- to 60-h old Wistar rat pups, averaging $6.5 \pm 0.6 \mathrm{~g}$ (Simonsen Laboratories, Gilroy, CA) were used for all studies. The pups were housed with their mother in a temperature-controlled room and kept under subdued light since birth. The mothers received food and water ad libitum. Animal handling, maintenance, and procedures were approved by the Institutional Animal Care and Use Committee at Stanford University.

Light sources. Blue LEDs (NSPB-500S, $5 \mathrm{~mm}, 462 \mathrm{~nm}$; Nichia Chemical Industries Ltd., Anan, Japan) and a combination of fluorescent tubes (one special blue, F20T12/BB, Philips, The Netherlands, and two cool white, F20T12/CW, Sylvania, Columbus, $\mathrm{OH}$ ) were used as light sources. The latter combination $(\mathrm{BB} / \mathrm{CW})$ was chosen to mimic the common practice at Lucile Salter Packard Children's Hospital to use alternating blue and white fluorescent lights to deliver phototherapy when blue LED devices are not available. Some spectral characteristics are summarized in Table 1.

CO production measurements. $\mathrm{CO}$ excretion $[\mu \mathrm{L} \mathrm{CO} / \mathrm{h} / \mathrm{kg}$ body weight, (BW)] was measured by gas chromatography using a Reduction Gas Analyzer (RGA-3; Ametek Process Instruments, Newark, DE) as previously described (8). For this study, $17-\mathrm{mL}(55 \times 20 \mathrm{~mm}$ inner diameter $)$ acrylic chambers (10) were adapted (Fig. 1A) to allow separate quantification of $\mathrm{CO}$ excretion from the total body, head only, and trunk only (Fig. 1B). All experiments were performed in a darkened lab and under temperaturecontrolled $\left(27 \pm 1^{\circ} \mathrm{C}\right)$ conditions.

Light exposure studies. Pups were randomly selected and placed into the modified chambers and then maximally $\left(360^{\circ}\right)$ exposed to fluorescent tube light delivered by one BB plus two CW tubes (Fig. $2 A$ ) at an irradiance of 70 $\mu \mathrm{W} / \mathrm{cm}^{2} / \mathrm{nm}$ or to a blue LED source containing 40 LEDs evenly arranged in

\footnotetext{
Abbreviations: BB, special blue fluorescent light; BW, body weight; CO, carbon monoxide; CW, cool white fluorescent light; ELBW, extremely low birth weight; LEDs, light emitting diodes
} 
eight strips of five bulbs placed around the circumference of the chamber (Fig. $2 B$ ) and operated at up to $24 \mathrm{VDC}$ and $0.43 \mathrm{~A}$ as previously described (10) affording us the ability to adjust and deliver irradiances of 25,50 , and 100 $\mu \mathrm{W} / \mathrm{cm}^{2} / \mathrm{nm}$. Control pups were housed in identical chambers and kept in the dark for the same time period. Each chamber was supplied with air at a flow rate of $20 \mathrm{~mL} / \mathrm{min}$ and kept at ambient temperature $\left(27 \pm 1^{\circ} \mathrm{C}\right)$ with the use of fans and monitored continuously.

Light intensity (irradiance) was measured using the Joey Dosimeter (Fiberoptic Medical Products, Inc., Allentown, PA) and reported in $\mu \mathrm{W} /$ $\mathrm{cm}^{2} / \mathrm{nm}$. This instrument, which is frequently used in hospitals, measures irradiance of the light only within a $420-550 \mathrm{~nm}$ wavelength range with a peak at $470 \mathrm{~nm}(6)$.

Effect of riboflavin. To test whether the presence of a photosensitizer, such as riboflavin, could exacerbate the light-mediated $\mathrm{CO}$ excretion, pups were given $10 \mu \mathrm{mol} / \mathrm{kg} \mathrm{BW}$ of riboflavin (vitamin B2; Sigma-Aldrich Chemical Co., St. Louis, MO) i.p. and then reexposed to fluorescent or blue LED light source at an irradiances of $70 \mu \mathrm{W} / \mathrm{cm}^{2} / \mathrm{nm}$ for $60 \mathrm{~min}$ as described earlier.

Table 1. Studied light sources and their characteristics

\begin{tabular}{clcc}
\hline \multicolumn{1}{c}{ Type of light } & Manufacturer & $\begin{array}{c}\text { Spectrum } \\
(\mathrm{nm})\end{array}$ & $\begin{array}{c}\text { Peak } \\
\text { wavelength } \\
(\mathrm{nm})\end{array}$ \\
\hline $\begin{array}{c}\text { Fluorescent } \\
\text { Two cool white } \\
(\mathrm{F} 20 \mathrm{~T} 12 / \mathrm{CW})\end{array}$ & Philips & $380-720$ & 578 \\
$\begin{array}{c}\text { One special blue } \\
(\mathrm{F} 20 \mathrm{~T} 12 / \mathrm{BB})\end{array}$ & Sylvania & $400-550$ & 445 \\
$\begin{array}{c}\text { Blue LEDs } \\
(\mathrm{NSPB}-500 \mathrm{~S}, 5 \mathrm{~mm})\end{array}$ & $\begin{array}{c}\text { Nichia Chemical } \\
\text { Corp. }\end{array}$ & $425-525$ & 462 \\
\hline
\end{tabular}

Calculations and statistics. The data are presented as mean \pm SD. Measured $\mathrm{CO}$ excretion in light is calculated as a percentage (\%) of measured $\mathrm{CO}$ excretion in the dark as follows:

$$
\% \text { of } \mathrm{CO}_{\text {dark }}=\left[\frac{\text { peak } \mathrm{CO}_{\text {light }}}{\text { mean } \mathrm{CO}_{\text {dark }}}\right] \times 100
$$

Statistical differences in \% of $\mathrm{CO}_{\text {dark }}$ between exposures to both light sources were determined by unpaired $t$ tests and deemed significant when $p \leq 0.05$.

\section{RESULTS}

Time course. During the 48-min cycled exposures to the dark and to either fluorescent light or a blue LED source at an irradiance of $70 \mu \mathrm{W} / \mathrm{cm}^{2} / \mathrm{nm}$ total body CO excretion rapidly increased from 41.0 to $78.9 \mu \mathrm{L}$ of $\mathrm{CO} / \mathrm{h} / \mathrm{kg} \mathrm{BW}$ (1.9-fold) and from 30.0 to $42.4 \mu \mathrm{L}$ of $\mathrm{CO} / \mathrm{h} / \mathrm{kg}$ BW (1.4-fold), respectively, over dark control levels (Fig. 2C). Peak CO excretion rates were reached at approximately the same time $(\sim 20 \mathrm{~min})$ during exposure to each light source. When the light was turned off, initially $\mathrm{CO}$ excretion rates fell rapidly, but then tailed-off more slowly. In addition, no appreciable production of $\mathrm{CO}$ was observed in empty chambers under dark or light exposures.

Source of CO excretion and irradiance response. To determine whether pulmonary $\mathrm{CO}$ excretion was increased or if $\mathrm{CO}$ was also excreted from the skin, head (predominantly pulmonary), and trunk $\mathrm{CO}$ excretion rates were measured separately during exposures to each light source (Fig. 3). Exposure to either light source did not increase significantly head $\mathrm{CO}$ excretion;
$\mathbf{A}$

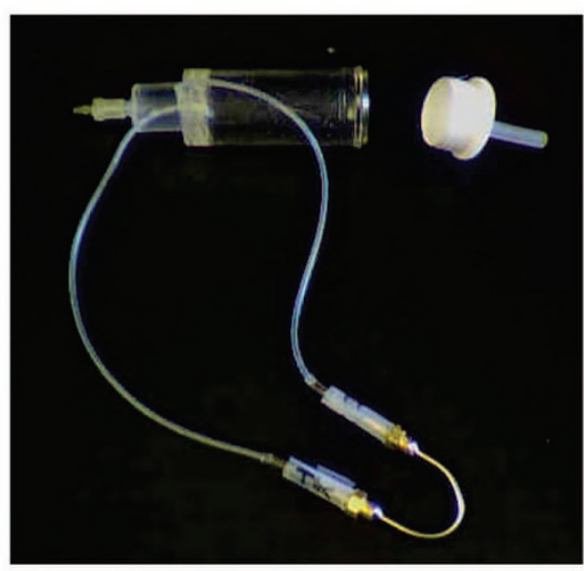

B

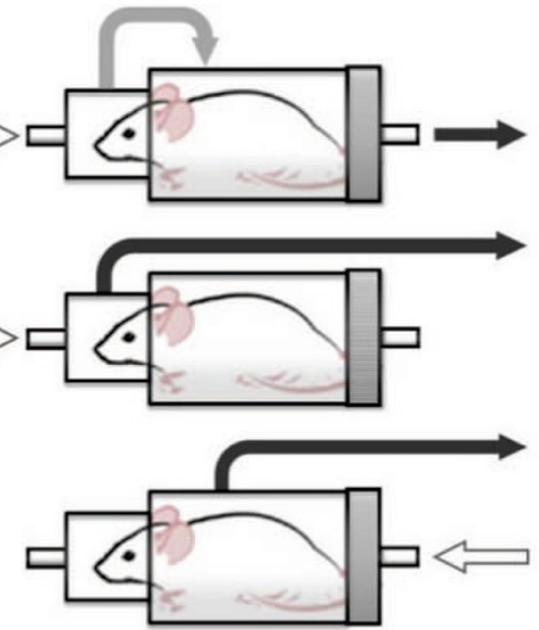

Figure 1. Sectional chamber. (A) Photograph of the sectional chamber and (B) diagram illustrating the sectional chambers used to separately sample carbon monoxide (CO) excreted by the total body (top), head (middle), or trunk (bottom).

Figure 2. $\mathrm{CO}$ excretion during cyclic light exposures. Experimental setups for delivering $360^{\circ}$ light exposures: (A) fluorescent light [one special blue (BB) plus two cool white $(\mathrm{CW})]$ and $(B)$ blue light emitting diodes (LEDs). (C) Total body CO excretion was measured during 48min cyclic "off" and "on" $360^{\circ}$ exposures to each light source, fluorescent light (๑); blue LEDs (O). Values are expressed as mean $\pm \mathrm{SD}$ fold change from $\mathrm{CO}$ excretion in the dark, $n=3$ animals exposed to each light source. 


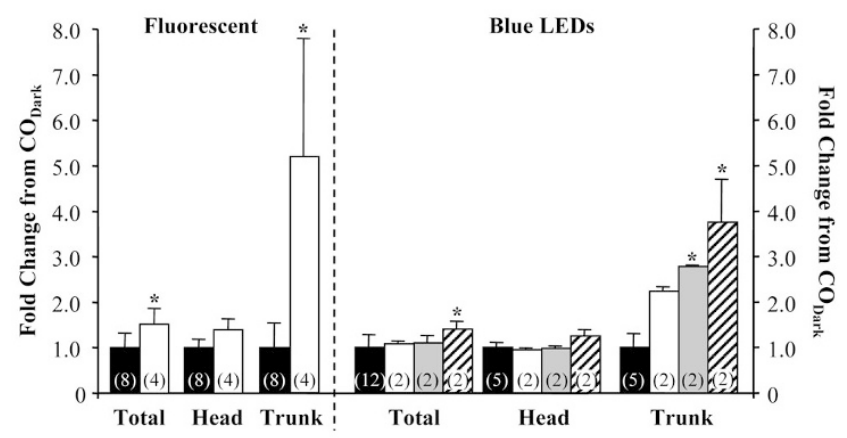

Figure 3. CO excretion as a function of light intensity. Total body, head, and trunk $\mathrm{CO}$ production were measured separately in pups exposed to the dark (ם); fluorescent light at $70 \mu \mathrm{W} / \mathrm{cm}^{2} / \mathrm{nm}$ [one special blue (BB) plus two cool white $(\mathrm{CW}), \square$ ]; and blue LEDs at increasing irradiances $\left(\mu \mathrm{W} / \mathrm{cm}^{2} / \mathrm{nm}\right): 25$ $(\square), 50(\square)$, and 100 (凹). Irradiance was measured using a Joey Dosimeter. Values are expressed as mean \pm SD fold change from $\mathrm{CO}$ excretion in the dark. Number of pups used in parentheses. ${ }^{*} p \leq 0.05$ compared with dark CO excretion rates for respective body section.

however, total body and trunk excretion increased to an average of 1.5-fold (from $36.9 \pm 11.0$ to $53.4 \pm 9.3 \mu \mathrm{L} \mathrm{CO}$ excreted $/ \mathrm{h} / \mathrm{kg}$ BW) and 4.4-fold (from $3.5 \pm 1.9$ to $15.5 \pm 4.6 \mu \mathrm{L} \mathrm{CO}$ excreted/h/kg BW), respectively.

Because we were able to adjust the light intensity delivered by blue LEDs, we performed an irradiance dose response at 25,50 , and $100 \mu \mathrm{W} / \mathrm{cm}^{2} / \mathrm{nm}$. We observed that at an irradiance of $100 \mu \mathrm{W} / \mathrm{cm}^{2} / \mathrm{nm}$, all body sections demonstrated significant increases in $\mathrm{CO}$ excretion rates. Trunk $\mathrm{CO}$ excretion was observed to proportionally increase with increasing light intensity (Fig. 3, right panel).

Effect of riboflavin on CO excretion. Administration of riboflavin $(10 \mu \mathrm{mol} / \mathrm{kg} \mathrm{BW})$, an endogenous photosensitizer present in variable concentrations in the circulation of neonates, increased total body $\mathrm{CO}$ excretion rates from 27.0 to $74.8 \mu \mathrm{L} \mathrm{CO} / \mathrm{h} / \mathrm{kg} \mathrm{BW}$ (2.8-fold) and from 23.9 to $49.3 \mu \mathrm{L}$ of $\mathrm{CO} / \mathrm{h} / \mathrm{kg} \mathrm{BW}$ (2.1-fold) over dark CO levels after exposures to the mixed blue/white fluorescent light or blue LED sources at $70 \mu \mathrm{W} / \mathrm{cm}^{2} / \mathrm{nm}$ (Fig. 4).

\section{DISCUSSION}

Phototherapy has been assumed to be safe for all infants despite a lack of experimental evidence in ELBW infants to support this assumption. As survival rates for such infants have improved over the years (11), more infants have been exposed to increasing intensities of light from a variety of sources, which deliver light at different wavelength ranges. Such exposure has been advocated for ELBW infants on a nearly universal basis because of the fear of bilirubin-induced neurotoxicity. Visible light can definitely penetrate tissue beyond the skin, as has been demonstrated for the purpose of imaging the brain (12). Moreover, bilirubin in circulation or other tissues may serve as an antioxidant and its elimination or destruction could limit further an already compromised antioxidant defense in the ELBW infant. This scenario especially might be true in ELBW infants receiving phototherapy. The combination of photooxidation and lipid peroxidation from other causes, exacerbated by depletion of bilirubin in tissues in

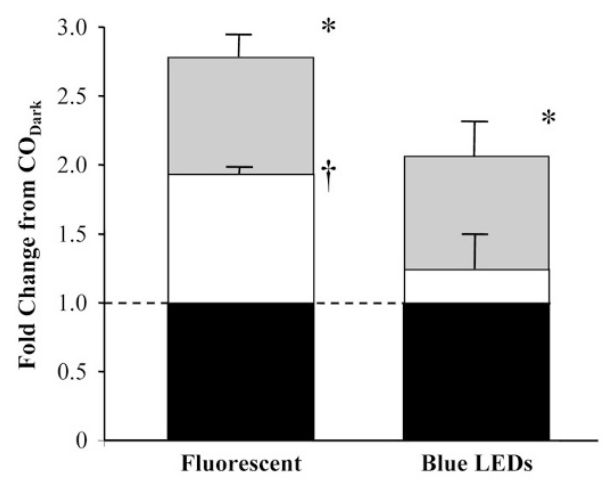

Figure 4. Effect of riboflavin on $\mathrm{CO}$ excretion during light exposures. Total body $\mathrm{CO}$ excretion rates were measured in pups in the dark ( $\square$, dark) and during exposure to fluorescent light [one special blue (BB) plus two cool white $(\mathrm{CW})]$ or blue LEDs in the absence ( $\square$, light only) or after the i.p. administration of $10 \mu \mathrm{mol}$ of riboflavin/ $\mathrm{kg}$ body weight $(\square$, Light $+R F)$ at an $70 \mu \mathrm{W} / \mathrm{cm}^{2} / \mathrm{nm}$ measured using a Joey Dosimeter. Values are shown as mean $\pm \mathrm{SD}$ fold change from $\mathrm{CO}$ excretion in the dark, $n=3$ animals studied per group. ${ }^{*} p \leq 0.05$ compared with dark and light Only CO excretion rates. $\dagger p \leq 0.05$ compared with dark CO excretion rates.

response to light, could place the ELBW infant at high-risk for light-induced injury, which needs to be considered in assessing the risk for bilirubin-induced injury. As suggested in the recent multicenter phototherapy trial (2), the balance of risk may differ depending upon the developmental vulnerabilities of the subjects, with the smaller, more translucent individuals demonstrating greater susceptibility to the effects of light. Although actual irradiances or the type of phototherapy devices used at each center was not stated this study, such effects could still be exacerbated by endogenous (e.g. riboflavin, porphyrins) or exogenous photosensitizers (13-15) (Vreman HJ et al. 2001 Effect of fluorescent- and LED blue light exposure on riboflavin-treated Gunn rat pups, In: PAS Annual Meeting; April 28-May 1, 2001; Baltimore, MD, Abstract $325 \mathrm{~A}$ ) or minimized by use of selective wavelengths of light such as that emitted by a blue LED source. Of course, bilirubin would not be the only target for photodegradation. We have observed that $\mathrm{CO}$ is generated from reduced NADPH in the presence of a photosensitizer after exposure to light (8). Thus, the administration of photosensitizers with concomitant use of phototherapy would be worrisome, because of the many possible candidates for oxidation in the exposed tissues, such as skin, eyes, and brain, and a diminished antioxidant status or singlet oxygen-trapping mechanisms of tissues in immature organisms.

We have shown clearly that $\mathrm{CO}$ excretion as an index of oxidation, is increased in Wistar rat pups exposed to phototherapy, arising mainly from the skin. Light emitted from a blue LED source even at $100 \mu \mathrm{W} / \mathrm{cm}^{2} / \mathrm{nm}$ (approximately two times that used clinically, see Ref. 6, Table 1), known to be effective in the photoisomerization of bilirubin, and in lowering circulating bilirubin levels, was the least photooxidizing, as evidenced by this methodology. Moreover, exposure to blue LED light at therapeutic ranges $\left(50 \mu \mathrm{W} / \mathrm{cm}^{2} / \mathrm{nm}\right.$ or less $)$ was not associated with an increase in $\mathrm{CO}$ production. Notably, fluorescent blue/white light at $70 \mu \mathrm{W} / \mathrm{cm}^{2} / \mathrm{nm}$ (a dose twice of that used clinically) caused larger increases in $\mathrm{CO}$ 
excretion, suggesting that other parts of the light spectrum, besides the blue part, might be more penetrating, including the yellow-red range, and perhaps even more oxidizing. Because of the irradiance meter used in this study and others used clinically measure only the blue part of the spectrum, the dose of light outside the target range remains unmeasured, but obviously may not be inconsequential as was seen in this study. That we did not observe significant increases in breath CO excretion with light exposure does not necessarily exclude the possibility of significant photooxidation or lipid peroxidation in deeper tissues like the brain. In addition, we observed that exogenous riboflavin could even increase $\mathrm{CO}$ excretion during blue light exposure. Furthermore, the broad wavelength band of $\mathrm{BB} / \mathrm{CW}$ fluorescent light combination, in contrast to a blue LED source, seems to activate riboflavin to a greater extent thereby generating more $\mathrm{CO}$ and may be because of its greater irradiance and mercury emission peaks. The predominant source of $\mathrm{CO}$ in breath is from the catabolism of heme, and even relatively large local increases in brain oxidation might be obscured by the large amounts of $\mathrm{CO}$ produced from total body heme catabolism. The binding of $\mathrm{CO}$ to local hemoproteins, combined with delayed diffusion out of tissues and into circulation, could have further blunted changes in breath $\mathrm{CO}$, making it less reflective of total body $\mathrm{CO}$ production. Although lipid peroxidation in the liver and lungs has been associated with increased $\mathrm{CO}$ excretion in breath, the tissue oxidative injury has been massive [e.g. carbon tetrachloride poisoning (16)] or involved a large surface area $[$ e.g. oxygen exposure in the lungs (17)], in the latter case directly contributing $\mathrm{CO}$ to alveolar gas. Thus, it is not surprising that the skin, a large surface area directly exposed to the oxidizing agent (in this case, light) contributed large amounts of $\mathrm{CO}$ into the collection chamber, and might serve as the "canary" for oxidative stress in the context of phototherapy. Further investigation in this regard seems warranted.

Although these studies were performed on very tiny (6.5 g) animals and our observations may not be directly applicable to human infants, we do hypothesize that oxidation induced by light exposure even for a short time or exacerbated by the light-induced lowering of bilirubin in circulation and tissues could have detrimental effects. Perhaps, at low levels, bile pigments, such as bilirubin, are contributors to antioxidant defense and neuronal protection $(18,19)$. Bilirubin prevents $\mathrm{CO}$ production from lipid peroxidation in vitro, potently inhibiting $\mathrm{CO}$ production by $50 \%$ at $4 \mu \mathrm{M}$ (9), which is well below the $3-6 \mathrm{mg} / \mathrm{dL}(51-103 \mu \mathrm{M})$ total bilirubin concentration range for healthy newborns. No causal relationship has been established between light exposure and the increased rate of death in the ELBW infants between 500 and $750 \mathrm{~g}$ in the recently reported study (2). Thus, the explanation for the increased rate of death among ELBW infants receiving aggressive phototherapy remains uncertain.

However, if it were decided that phototherapy needs to be used in the smallest babies (501-750 g), a device delivering narrow wavelength light, such as a blue LED source, would seem to be the prudent choice. Also, the search for nonphotosensitizing alternative pharmaceutical approaches to the management of neonatal jaundice in ELBW infants is still needed.

Acknowledgment. We thank Antony F. McDonagh, Ph.D., for his critical review of the manuscript.

\section{REFERENCES}

1. Maisels MJ, Watchko JF 2003 Treatment of jaundice in low birthweight infants. Arch Dis Child Fetal Neonatal Ed 88:F459-F463

2. Morris BH, Oh W, Tyson JE, Stevenson DK, Phelps DL, O'Shea TM, McDavid GE, Perritt RL, Van Meurs KP, Vohr BR, Grisby C, Yao Q, Pedroza C, Das A, Poole WK, Carlo WA, Duara S, Laptook AR, Salhab WA, Shankaran S, Poindexter BB, Fanaroff AA, Walsh MC, Rasmussen MR, Stoll BJ, Cotten CM, Donovan EF, Ehrenkranz RA, Guillet R, Higgins RD 2008 Aggressive vs. conservative phototherapy for infants with extremely low birth weight. N Engl J Med 359:1885-1896

3. Brown AK, Kim MH, Wu PY, Bryla DA 1985 Efficacy of phototherapy in prevention and management of neonatal hyperbilirubinemia. Pediatrics 75:393-400

4. Sisson TR 1987 Photodegradation of riboflavin in neonates. Fed Proc 46:1883-1885

5. Tozzi E, Tozzi-Ciancarelli MG, Di Giulio A, D'Alfonso A, Farello G, Spennati GF, de Matteis F 1989 In vitro and in vivo effects of erythrocyte phototherapy on newborns. Biol Neonate 56:204-209

6. Vreman HJ, Wong RJ, Stevenson DK 2004 Phototherapy: current methods and future directions. Semin Perinatol 28:326-333

7. Gopinathan V, Miller NJ, Milner AD, Rice-Evans CA 1994 Bilirubin and ascorbate antioxidant activity in neonatal plasma. FEBS Lett 349:197-200

8. Vreman HJ, Gillman MJ, Downum KR, Stevenson DK 1990 In vitro generation of carbon monoxide from organic molecules and synthetic metalloporphyrins mediated by light. Dev Pharmacol Ther 15:112-124

9. Vreman HJ, Wong RJ, Sanesi CA, Dennery PA, Stevenson DK 1998 Simultaneous production of carbon monoxide and thiobarbituric acid reactive substances in rat tissue preparations by an iron-ascorbate system. Can J Physiol Pharmacol 76:10571065

10. Vreman HJ, Wong RJ, Chan ML, Young BW, Stevenson DK 2006 Transcutaneous bilirubinometry: a noninvasive tool for studying newborn jaundiced rats before and after exposure to light. Pediatr Res 59:203-209

11. Fanaroff AA, Wright LL, Stevenson DK, Shankaran S, Donovan EF, Ehrenkranz RA, Younes N, Korones SB, Stoll BJ, Tyson JE, Bauer CR, Oh W, Lemons JA, Papile LA, Verter J 1995 Very-low-birth-weight outcomes of the National Institute of Child Health and Human Development Neonatal Research Network, May 1991 through December 1992. Am J Obstet Gynecol 173:1423-1431

12. Hintz SR, Cheong WF, van Houten JP, Stevenson DK, Benaron DA 1999 Bedside imaging of intracranial hemorrhage in the neonate using light: comparison with ultrasound, computed tomography, and magnetic resonance imaging. Pediatr Res 45:54-59

13. McDonagh AF, Palma LA 1985 Tin-protoporphyrin: a potent photosensitizer of bilirubin destruction. Photochem Photobiol 42:261-264

14. Ballowitz L, Bunjamin A, Hanefeld F, Lietz L, Stuttgen G, Wirjadi D 1979 Effects of riboflavin on Gunn rats under phototherapy. Pediatr Res 13:1307-1315

15. Sanvordeker DR, Kostenbauder HB 1974 Mechanism for riboflavin enhancement of bilirubin photodecomposition in vitro. J Pharm Sci 63:404-408

16. Lindstrom TD, Anders MW, Remmer H 1978 Effect of phenobarbital and diethyl maleate on carbon tetrachloride toxicity in isolated rat hepatocytes. Exp Mol Pathol 28:48-57

17. May C, Patel S, Peacock J, Milner A, Rafferty GF, Greenough A 2007 End-tidal carbon monoxide levels in prematurely born infants developing bronchopulmonary dysplasia. Pediatr Res 61:474-478

18. Dennery PA, McDonagh AF, Spitz DR, Rodgers PA, Stevenson DK 1995 Hyperbilirubinemia results in reduced oxidative injury in neonatal Gunn rats exposed to hyperoxia. Free Radic Biol Med 19:395-404

19. Stocker R, Glazer AN, Ames BN 1987 Antioxidant activity of albumin-bound bilirubin. Proc Natl Acad Sci USA 84:5918-5922 